\title{
Migration of contaminants from milk tubes and teat liners
}

\section{Ruuska, R.M.}

International Association for Food Protection

1987

Journal of food protection. 1987. 50: 316-320

http://hdl.handle.net/1975/754

Downloaded from Helda, University of Helsinki institutional repository.

This is an electronic reprint of the original article.

This reprint may differ from the original in pagination and typographic detail.

Please cite the original version. 


\title{
Migration of Contaminants from Milk Tubes and Teat Liners
}

\author{
RISTO M. RUUSKA ${ }^{1}$, HANNU KORKEALA ${ }^{1 *}$, HELENA LIUKKONEN-LILJA ${ }^{2}$, TAPANI SUORTTI ${ }^{2}$, and KALEVI SAL- \\ MINEN $^{3}$
}

Department of Food and Environmental Hygiene, College of Veterinary Medicine, P. O. Box 6, SF-0055I Helsinki, Finland, Food Research Laboratory. Technical Research Centre of Finland, and Veterinary Department, Ministry of Agriculture and Forestry

(Received for publication June 3, 1986)

\section{ABSTRACT}

The survey tested migration of contaminants from various flexible tubes and teat liners used in milk production. A total of 19 samples were analyzed through sensory evaluation and in migration tests with different simulant liquids. Plasticizers were dissolved in diethyl ether or tetrahydrofuran and analyzed in high performance liquid chromatography (HPLC). The most widely used polyvinyl chloride (PVC) tubes contained $37-40 \%$ di-2-ethylhexyl phthalate (DEHP) as plasticizer. In some tubes DEHP was to a great extent replaced by a polymeric plasticizer. DEHP was analyzed with reverse phase HPLC directly from milk in a procedure in which a piece of tube was soaked in milk for 1, 3 and $6 \mathrm{~d}$. Tubes containing polymeric plasticizer lost less DEHP into milk, but relatively more than the tubes plasticized only by DEHP. The evaporation residue for migration tests to water was significantly greater for polyadipate tubes compared with tubes plasticized only by DEHP. The evaporation residue from the water extract of the tubes plasticized by polymeric plasticizer was by mass-spectral analysis found to consist of various hydrolyzation products of polyester from 1,3-butandiol and adipic acid. The results obtained are discussed in the light of toxicological problems connected with plasticizers.

Contamination of milk by migrating plasticizers from milk tubes has been reported several times. According to Kiermeier et al. (9) phthalate esters can migrate into milk from polyvinyl chloride (PVC) tubes. Mueller and Bradley (13) also reported that a phthalate ester plasticizer can be leached from PVC tubes used in milk production. There is some evidence that residues of phthalates occur in milk. For example, Cerbulis and Ard (3) found 80 ppm dioctylphthalate (DOP) in the fat of a single milk sample. Further, Leoni et al. (12) reported that in Italy the pollution level of milk by phthalate plasticizers ranges between 2 and $600 \mathrm{ppm}$ in the fat extract. Migration of plasticizers from PVC films to cheese is also well documented (16).

Di-2-ethylhexyl phthalate (DEHP) is the most commonly used plasticizer of PVC. The plasticizer forms about $40 \%$ of the final weight of the polymeric material. The plasticizer is implemented to give flexibility to the polymer. DEHP is practically insoluble in water, but is soluble in fat (4). Therefore, for example, in the Federal Republic of Germany, the DEHP content in milk tubes is restricted to $10 \%$ (2). DEHP can be replaced to a large extent by polyester plasticizers, which are usually polyesters of 1,3-butanediol and adipic acid (polyadipates). DEHP is still used as a secondary plasticizer. Polyadipates are practically insoluble in fat, but are soluble in water to a limited extent.

The toxicity of phthalates has been the subject of keen interest in recent decades. DEHP is without doubt the best known plasticizer from the toxicological point of view. Its acute toxicity is quite low and it was considered for a long time to be quite safe. It was only in the 1980s, in the long term carcinogenicity tests by the National Toxicology Program in the USA that it was noted that oral administraton of DEHP may cause liver tumors in rats and mice (10).

Synthetic rubber is occasionally used in milk tubes instead of plasticized PVC. The teat liners also contain synthetic rubber. Those tubes and teat liners may also contain DEHP.

The toxicity of polymeric plasticizers, which are widely recommended as a replacement for DEHP under critical conditions, is largely unresolved.

The purpose of this study was to examine the properties of different milk tubes and teat liners used in Finland, and to find out the capacity of plasticizers such as DEHP to contaminate milk.

MATERIALS AND METHODS

'College of Veterinary Medicine.

${ }^{2}$ Technical Research Centre of Finland.

${ }^{3}$ Ministry of Agriculture and Forestry.
Samples

Tubes and teat liners for milking machines were purchased 
TABLE 1. Sensory analysis ${ }^{a}$ of milk tubes and teat liners.

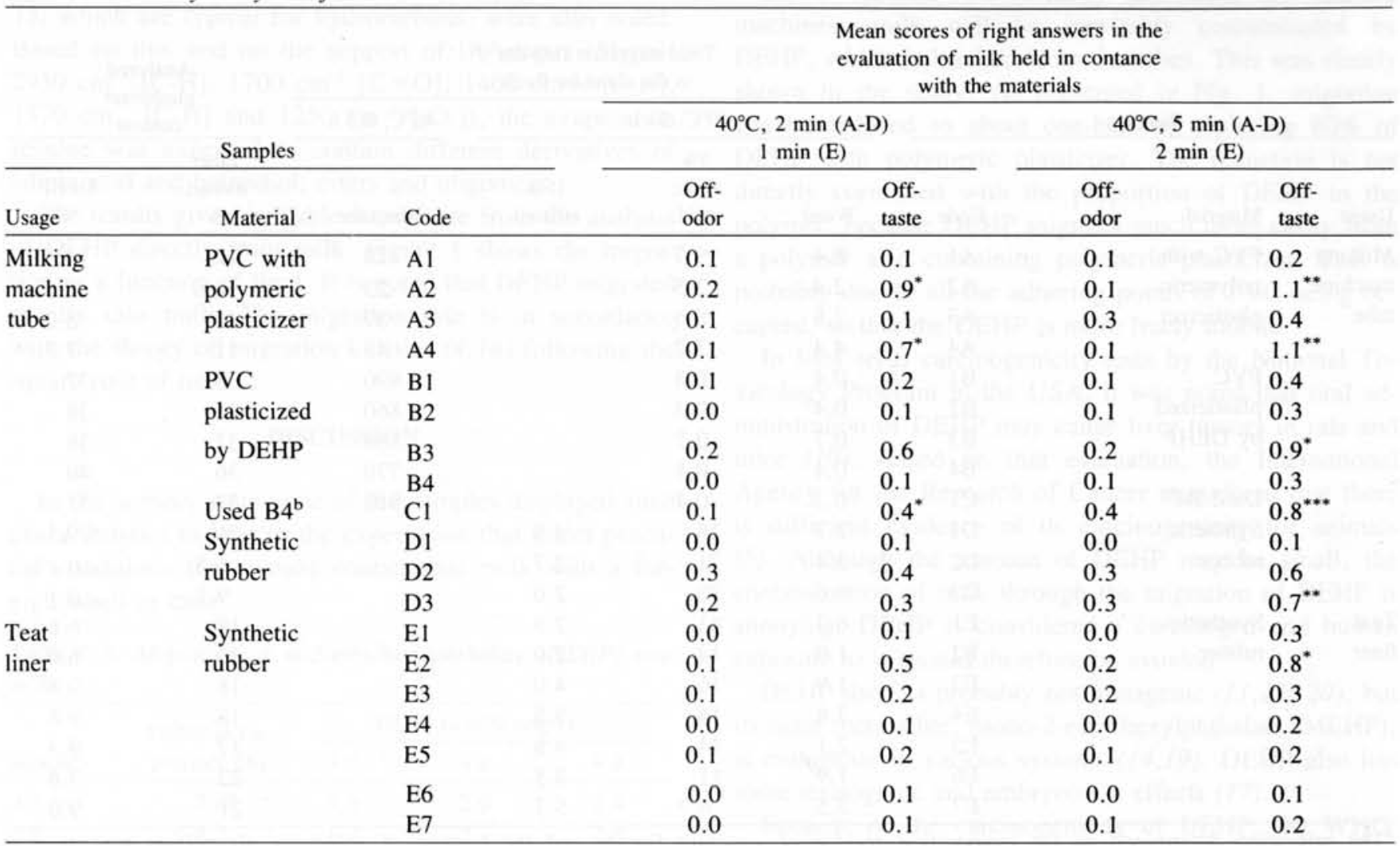

a The samples were presented in a modified triangle test to a panel of ten experienced persons.

The significance of correct answers is indicated by asterix:

${ }^{*} \mathrm{p}<0.05$ if $7 / 10$ correct answers are given.

${ }^{* *} \mathrm{p}<0.01$ if $8 / 10$ correct answers given.

${ }^{* * *} p<0.001$ if $9 / 10$ or more correct answers are given.

Further, the intensity of off-taste and off-odor is calculated. On the scale 0-3 3 points indicates a strong off-odor or off-taste while 0 was given when no off-odor or off-taste was detected.

${ }^{b}$ The tube had been used for 10 months daily and during that period $37,000 \mathrm{~kg}$ of milk had passed through the tube.

from the Finnish market. There were 11 different samples of new and unused milk tubes, of which 8 were PVC tubes and 3 rubber tubes. One used PVC tube $(\mathrm{C} 1)$ was also included in the tests. This sample was of the same origin as tube B4, but it had been in daily use on a farm for 10 months, and during that period $37,000 \mathrm{~kg}$ of milk had passed through the tube. The number of teat liner samples was 7 in total. The samples originated from domestic and foreign manufacturers. The imported ones were from Denmark, Sweden, Federal Republic of Germany, France and New Zealand. The market coverage of these tubes and teat liners was over $99 \%$. Before the tests were done, all samples were washed in water with a neutral detergent. Parallel samples were tested in all procedures. Different types of samples were coded in series A to $\mathrm{E}$ as shown in Table 1.

\section{Sensory tests}

The sensory evaluation was carried out using a modified triangle test. Milk $\left(40^{\circ} \mathrm{C}\right)$ was retained in milk tubes for 2 and $5 \mathrm{~min}$, and in teat liners for 1 and $2 \mathrm{~min}$. The control milk $\left(40^{\circ} \mathrm{C}\right)$ was retained in a beaker at the same time. After refrigeration to $20^{\circ} \mathrm{C}$ the milk samples were presented to a laboratory panel of 10 experienced persons. Each sample was evaluated against two control samples in the triangle test. The test person was asked, which of the three samples was a different one.
The number of right answers was analyzed statistically (I). Further, the test persons were asked to evaluate on a scale of 0-3 points the intensity of possible off-odor or off-taste. A score of 3 indicated a strong off-odor or off-taste, while 0 was given when no off-odor or off-taste was detected. The mean scores of right answers were then calculated.

\section{Chemical composition of materials}

The composition of the samples was determined by HPLC. The samples were refluxed with diethyl ether. The extracts were dried, dissolved in methanol and injected into the HPLC instrument. The equipment consisted of a M-6000 A pump, M-710B automatic injector, a Nova-Pak $\mathrm{C} 18$ column $(8 \times 100 \mathrm{~mm})$ in a RCM-100 column chamber and a modified dual-channel M$440 \mathrm{UV}$-vis detector monitoring at 254 and $280 \mathrm{~mm}$ (All from Millipore/Waters, USA). The eluent was methanol-water (95:5) at a flow-rate of $2 \mathrm{ml} / \mathrm{min}$. The PVC samples were dissolved directly in tetrahydrofuran (THF), filtered and injected into the HPLC instrument. The mobile phase was THF at a flow rate of $1 \mathrm{ml} / \mathrm{min}$ and the columns were Styragel $500 \mathrm{~A}$ and $100 \mathrm{~A}$ in series.

\section{Global migration tests}

Total migration from the materials was determined in various simulant liquids. The simulants for PVC tubes were water 


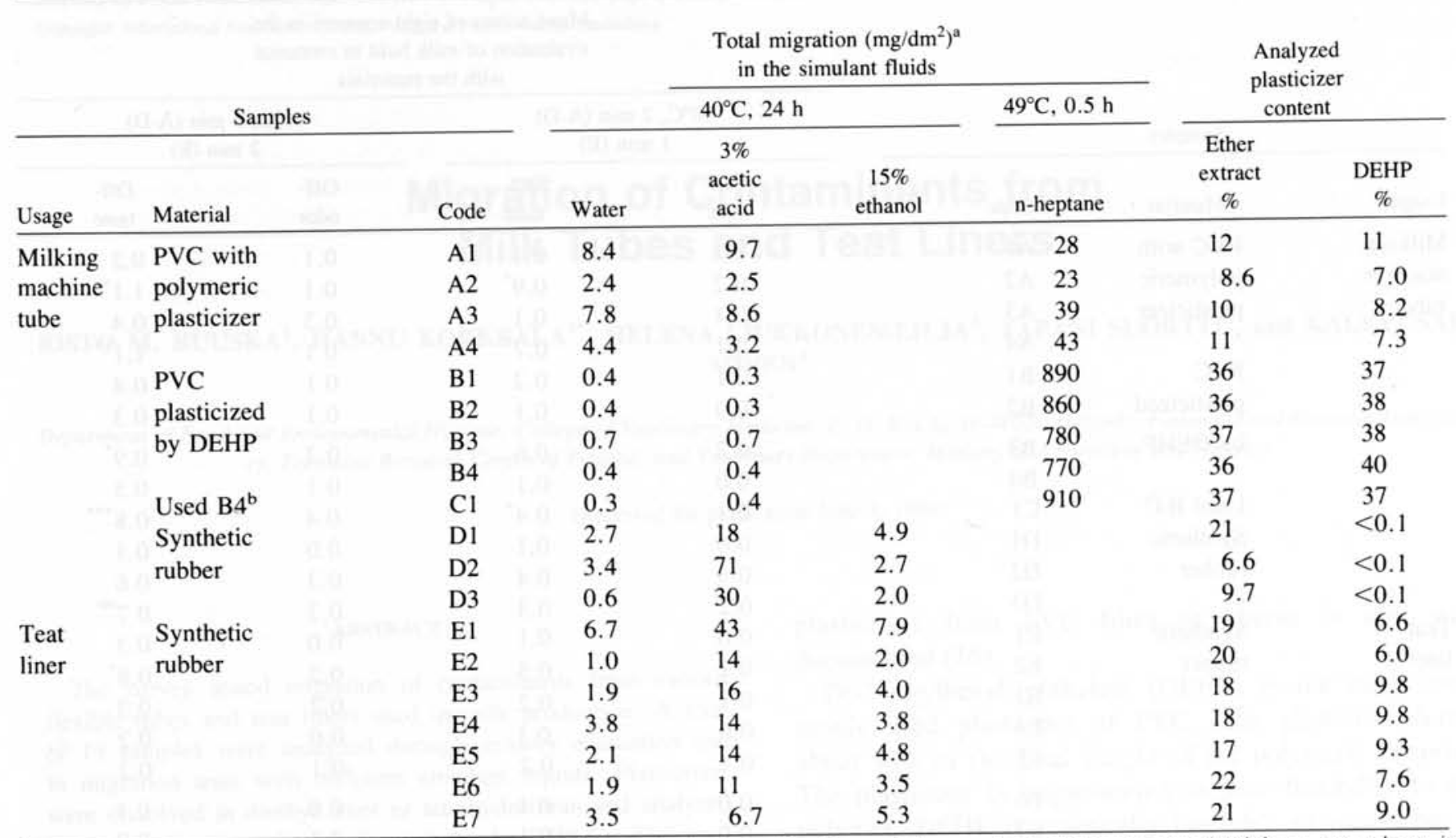

aThe migration determined as the evaporation residue of simulant liquids and the content of monomer plasticizers are given in the table. The results are means of parallel determinations with all procedures.

${ }^{6}$ The tube had been used for 10 months daily and during that period $37,000 \mathrm{~kg}$ of milk had passed through the tube.

$\left(40^{\circ} \mathrm{C}, 24 \mathrm{~h}\right), 3 \%$ acetic acid $\left(40^{\circ} \mathrm{C}, 24 \mathrm{~h}\right)$ and $\mathrm{n}$-heptane $\left(49^{\circ} \mathrm{C}\right.$, $0.5 \mathrm{~h})$; for rubber tubes and teat liners, $15 \%$ ethanol $\left(40^{\circ} \mathrm{C}\right.$, $24 \mathrm{~h}$ ) was used instead of $\mathrm{n}$-heptane. The evaporation residues of each simulant were weighed and divided by the inner surface areas of the samples.

\section{Analysis of the evaporation residues}

Further, the amount of DEHP in some of the n-heptane evaporation residues was determined by HPLC. For the water extract of two polyadipate tubes the IR-spectra were registered (Perkin-Elmer 683, USA) and the extracts were analyzed in a gas chromatograph (Hewlett-Packard 5790) equipped with mass selective detector (Hewlett Packard 5970, USA) and OV-1 silica capillar column operated $50-275^{\circ} \mathrm{C}, 10^{\circ} \mathrm{C} / \mathrm{min}$.

\section{Migration of DEHP into milk}

To analyze DEHP directly from milk as a result of migration 4 different PVC tube samples (tubes A2, A3, B4 and C1) were leached in milk at $40^{\circ} \mathrm{C}$ for 1,3 and $6 \mathrm{~d}$. Twenty-milliliter milk samples were mixed with $60 \mathrm{ml}$ of methanol and centrifuged $2500 \times g$ for $15 \mathrm{~min}$. Samples of $50 \mu \mathrm{l}$ were injected into the HPLC instrument equipped with a Nova-Pak C18 column. The mobile phase was acetonitrile: water (95:5) and detection was at $214 \mathrm{~mm}$ and at $254 \mathrm{~nm}$. Vials for the automatic injector were sealed with aluminum foil to avoid contamination of the samples.

\section{RESULTS}

The sensory evaluation of the samples is presented in Table 1. According to the results, the milk in a few in- stances was affected by a weak foreign taste.

The results of migration tests and other chemical tests are presented in Table 2. In the PVC tubes and teat liners, the amount of DEHP ranged between 6.6 and $40 \%$. In the synthetic rubber tubes DEHP was not found, but they may contain some non-phthalate plasticizer.

The n-heptane extract from polyadipate tubes (A1-A4) was significantly lower (Student's t-test; $\mathrm{p}<0.001$ ) than that from DEHP tubes $(\mathrm{B} 1-\mathrm{C} 1)$. The mean and standard deviations were $33 \mathrm{mg} / \mathrm{dm}^{2}$ and $9 \mathrm{mg} / \mathrm{dm}^{2}$ in polyadipate tubes, compared to $830 \mathrm{mg} / \mathrm{dm}^{2}$ and $59 \mathrm{mg} / \mathrm{dm}^{2}$ in DEHP tubes. On the other hand, total migration from PVC tubes plasticized by polyadipate and DEHP only as a secondary plasticizer (A1-A4) was significantly (Student's t-test; $\mathrm{p}<$ 0.01 ) greater into water (the mean and standard deviation $5.8 \mathrm{mg} / \mathrm{dm}^{2}$ and $2.9 \mathrm{mg} / \mathrm{dm}^{2}$, respectively) than from PVC tubes plasticized by DEHP only (B1-C1) (mean and standard deviation $0.47 \mathrm{mg} / \mathrm{dm}^{2}$ and $0.18 \mathrm{mg} / \mathrm{dm}^{2}$ ).

The n-heptane extract from tubes $\mathrm{Bl}-\mathrm{Cl}$ was $80 \%$ DEHP. This explains why total migration to n-heptane was so high from tubes $\mathrm{Bl}-\mathrm{Cl}$; the evaporation residue consisted mainly of DEHP. From other tubes the quantitative total migration to $n$-heptane was lower because of a lesser proportion of DEHP in the material and differences in chemical binding.

In the GLC-MS analysis of the water extracts of polyadipate tubes there was noted a high mass peak at $\mathrm{m} / \mathrm{e}=129$ with a strong signal. This is typical for the 
esters of adipic acid. Signals $\mathrm{m} / \mathrm{e}=43,55,57,71$ and 73 , which are typical for hydrocarbons, were also noted. Based on this and on the support of IR-spectra (Signals $2950 \mathrm{~cm}^{-1}$ [C-H], $1700 \mathrm{~cm}^{-1}$ [C=O], $1460 \mathrm{~cm}^{-1}$, [C-H], $1370 \mathrm{~cm}^{-1}[\mathrm{C}-\mathrm{H}]$ and $\left.1250 \mathrm{~cm}^{-1}[-\mathrm{O}-]\right)$, the evaporation residue was expected to contain different derivatives of adipic acid and butandiol; esters and oligomers.

The results given in Table 3 originate from the analysis of DEHP directly from milk. Figure 1 shows the migration as a function of time. It is noted that DEHP migrated rapidly into milk. The migration rate is in accordance with the theory of migration kinetics $(4,18)$ following the square root of time.

\section{DISCUSSION}

In the sensory tests none of the samples displayed such characteristics to lead to the expectation that under practical conditions they would contaminate milk with a foreign smell or taste.

TABLE 3. Migration of di-2-ethylhexylphthalate (DEHP) into milk.

\begin{tabular}{lcccc}
\hline & \multirow{2}{*}{$\begin{array}{c}\text { DEHP in the } \\
\text { pample }\end{array}$} & \multicolumn{3}{c}{ DEHP in milk (mg/1) } \\
\cline { 3 - 5 } & polymer (\%) & $1 \mathrm{~d}$ & $3 \mathrm{~d}$ & $6 \mathrm{~d}$ \\
\hline $\mathrm{A} 2$ & $7.0^{\mathrm{b}}$ & 1.3 & 2.0 & 2.4 \\
$\mathrm{~A} 3$ & 8.2 & 1.2 & 2.1 & 2.8 \\
$\mathrm{~B} 4$ & 40 & 1.9 & 3.3 & 5.0 \\
$\mathrm{Cl}^{\mathrm{c}}$ & 37 & 1.9 & 2.9 & 3.9 \\
\hline
\end{tabular}

${ }^{\mathrm{a}} 10-\mathrm{cm}$ pieces of PVC milk tubes were soaked in $500 \mathrm{ml}$ of milk for 1,3 and $6 \mathrm{~d}$ and DEHP. was analyzed from the milk by HPLC.

${ }^{b}$ Tubes $\mathrm{A} 2$ and $\mathrm{A} 3$ contained $32 \%$ polyadipate.

'Tube $\mathrm{Cl}$ was the same as B4, but after it had been in use for 10 months on a farm; $37,000 \mathrm{~kg}$ of milk had passed through the tube.

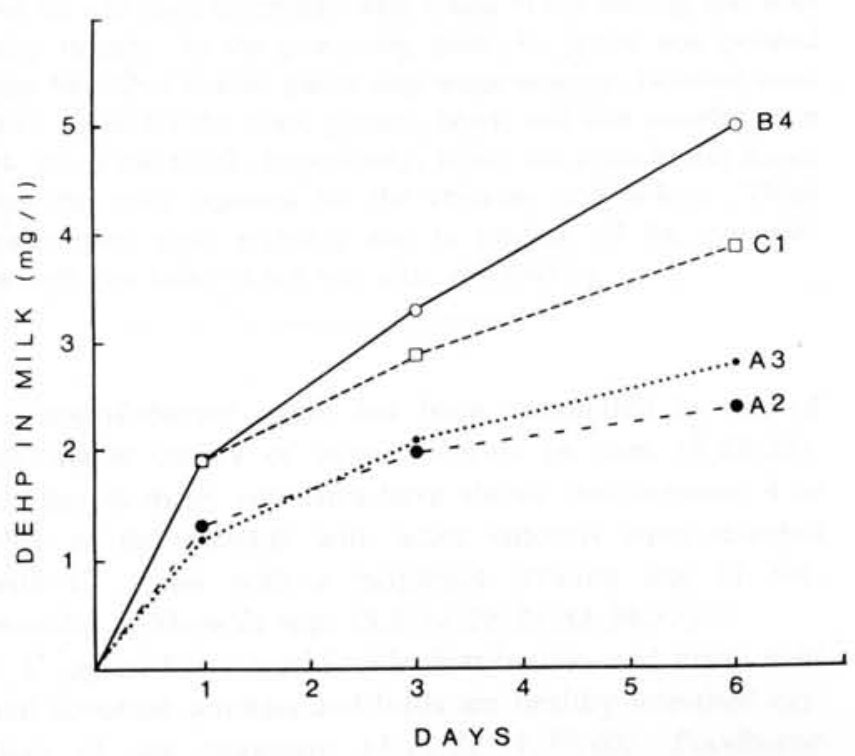

Figure 1. Migration of DEHP as a function of time; $10-\mathrm{cm}$ pieces of PVC milk tubes were soaked in milk and DEHP was analyzed from milk samples by HPLC. The plasticizer compound of the tubes is shown in Table 2.
When flexible PVC tubes are used in milking machines, milk will be inevitably contaminated by DEHP, which is leached from the tubes. This was clearly shown in the study. As presented in Fig. 1, migration can be reduced to about one-half by replacing $80 \%$ of DEHP with polymeric plasticizer. The reduction is not directly correlated with the proportion of DEHP in the polymer, because DEHP migrates much more easily from a polymer also containing polymeric plasticizer. This is probably due to all the adhering points of PVC being occupied, so that the DEHP is more freely mobile.

In long term carcinogenicity tests by the National Toxicology Program in the USA, it was noted that oral administration of DEHP may cause liver tumors in rats and mice $(10)$. Based on that evaluation, the International Agency for the Research of Cancer considered that there is sufficient evidence of its carcinogenicity for animals (5). Although the amount of DEHP may be small, the contamination of milk through the migration of DEHP is annoying. DEHP is considered a carcinogen and human exposure to it should therefore be avoided.

DEHP itself is probably not mutagenic $(11,15,20)$, but its main metabolite, mono-2-ethylhexylphthalate (MEHP), is mutagenic in various systems $(14,19)$. DEHP also has some teratogenic and embryotoxic effects (17).

Because of the carcinogenicity of DEHP, the WHO/ FAO Joint Expert Committee for the Evaluation of Food Additives and Contaminants has recommended that human exposure to DEHP in food as a result of its migration from food-contact materials should be reduced to the lowest technologically attainable level, and it can be only provisionally accepted if no satisfactory alternative exists (8).

The biological effects of hydrolyzation products of polyadipates are unknown. But they are water-soluble and are not expected to accumulate in organs. Today there is no evidence that residues from hydrolyzed esters of 1,3-butanediol and adipic acid are harmful from the toxicological point of view. As food additives JECFA has recommended an acceptable daily intake (ADI) not exceeding $5 \mathrm{mg} / \mathrm{kg}$ for adipic acid (6) and $4 \mathrm{mg} / \mathrm{kg}$ for $1,3-$ butanediol (7).

Today polyadipates are an alternative to replace DEHP in food contact materials, but their toxicology remains unresolved to such an extent that they can not be recommended without reservations.

\section{ACKNOWLEDGMENTS}

Financial support was provided by the Ministry of Agriculture and Forestry and by Walter Ehrström Foundation, Helsinki, Finland.

\section{REFERENCES}

1. Anonymous. 1948. Significance of triangular tests. J. Food Sci. 13:503-505.

2. Bundesgesundheitsamt. 1967. Mitteilungen aus dem Bundesgesundheitsamt; Gesundheitliche Beurteilung von Kunststoffen in Rahmen des Lebensmittelgesetzes; 40 mitteilung XXXVIII: Milch- und Zitzenschläuche aus Kunststoffen und Gummi. Bundesgesundheitsblatt 10:316. 
3. Cerbulis, J., and J. S. Ard. 1967. Method for isolation and detection of dioctyl phthalate from milk lipids. J. Assoc. Off. Anal. Chem. 50:646-650.

4. Graham, P. R. 1973. Phthalate ester plasticizers - why and how they are used. Environ. Health Perspesct. 3:3-12.

5. IARC. 1982. Evaluation of the carcinogenic risk of chemicals to humans. Some industrial chemicals and dyestuffs. International Agency for Research of Cancer Monographs No. 29, 16-21, $257-$ 267, 269-294.

6. JECFA. 1978. Evaluation of certain food additives. Twenty-first Report of the Joint FAO/WHO Expert Committee on Food Additives, World Health Organization Technical Report Series No. 617 , WHO, Geneva.

7. JECFA. 1980. Evaluation of certain food additives. Twenty-third Report of the Joint FAO/WHO Expert Committee on Food Additives, World Health Organizaton Technical Report Series No. 648, WHO, Geneva.

8. JECFA. 1984. Evaluation of certain food additives. Twenty-eighth Report of the Joint FAO/WHO Expert Committee on Food Additives and Contaminants, World Health Organization Technical Report Series No. 710, WHO, Geneva.

9. Kiermeier, F., K. W. Evers, and G. Wildbrett. 1969. Untersuchungen und Betrachtungen zur Anwendung von Kunststoffen für Lebensmittel. XIV Mitteilung. Erfahrungen mit einem praxisnahen Prufverfahren für Milchschläuche. Dtsch Lebensm. Rundsch. 65:305-311.

10. Kluwe, W. M., J. K. Haseman, J. F. Douglas, and J. E. Huff. 1982. The carcinogenicity of dietary di(2-ethylhexyl)phthalate (DEHP) in Fischer 344 rats and B6C3F1 mice. J. Toxicol. Environ. Health 10:797-815.

11. Kozumbo, W. J., R. Kroll, and R. J. Rubin. 1982. Assessment of the mutagenicity of phthalate esters. Environ. Health Perspect. 45:103-109.
12. Leoni, V., G. Puccetti, and S. Lagorio. 1981. Plastificanti a base di ftalati nel latte alimentare. Nuovi Ann. Ig. Microbiol. 32:253265.

13. Mueller, J. S., and R. L. Bradley, Jr. 1980. Loss of phthalic acid ester from polyvinyl chloride tubing into various fluids. J. Food Prot. 43:551-554.

14. Phillips, B. J., T. E. B. James, and S. D. Gangolli. 1982. Genotoxicity studies of di(2-ethylhexyl)phthalate and its metabolites in CHO cells. Mutat. Res. 102:297-304.

15. Putman, D. L., W. A. Moore, L. M. Schechtman, and J. R. Hodgson. 1983. Cytogenetic evaluation of di(2-ethylhexyl)phthalate and its major metabolites in Fischer 344 rats. Environ. Mutagen. 5:227-231.

16. Sandberg, E., R. Vaz, L. Albanus, P. Mattson, and K. Nilsson. 1982. Förorening i livsmedel av mjukgörande ämnen från plastfilm. Vår Föda 34:470-482.

17. Shiota, K., and H. Nishimura. 1982. Teratogenicity of di(2ethylhexyl)phthalate (DEHP) and di-n-butyl phthalate (DBP) in mice. Environ. Health Perspect. 45:65-70.

18. Till, D. E., R. C. Reid, P. S. Schwartz, K. R. Sidman, J. R. Valentine, and R. H. Whelan. 1982. Plasticizer migration from polyvinyl chloride film to solvents and foods. Food Chem. Toxicol. 20:95-104.

19. Tomita, I., Y. Nakamura, N. Aoki, and N. Inui. 1982. Mutagenic/ carcinogenic potential of DEHP and MEHP. Environ. Health Perspect. 45:119-125.

20. Yoshikawa, K., A. Tanaka, T. Yamaha, and H. Kurata. 1983. Mutagenic study of nine monoalkyl phthalates and a dialkyl phthalate using Salmonella typhimurium and Escherichia coli. Food Chem. Toxicol. 21:221-223. 